\section{La previsibilidad contractual y sus consecuencias en el Código Civil y Comercial}

The contractual predictability and its consequences in the Civil and Commercial Code

\section{Juan Francisco González Freire}

\section{I.- EXORDIO}

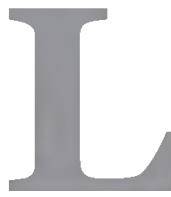

a temática que se abordará en el presente trabajo se relaciona con los efectos jurídicos que surgen de lo previsto en materia contractual; sea cual fuere el ámbito o las cuestiones por las cuales las partes exteriorizan su voluntad al momento de pactar. El Legislador ha contemplado las consecuencias jurídicas a través del vigente artículo 1728 del Código Civil y Comercial, señalando textualmente en cuanto a la "previsibilidad contractual", que "En los contratos se responde por las consecuencias que las partes previeron o pudieron haber previsto al momento de su celebración"; obviamente basándose en un obrar culposo, habida cuenta de que la culpa se presume cuando el factor de atribución no pueda establecerse con claridad al momento de demostrar el incumplimiento (cfr. art. 1721 y 1724, CCC).

Cuando existe dolo en el obrar del deudor, la responsabilidad se fija tomando en cuenta estas consecuencias también al momento del incumplimiento a sabiendas de que la intencionalidad de apartarse de lo oportunamente pactado conlleva un marco de juzgamiento mucho más riguroso.

Conforme a ello, la voluntad del Legislador refleja la necesidad de establecer las consecuencias resarcibles provenientes del incumplimiento de una obligación preexistente, cuya interpretación trae aparejadas algunas consideraciones que merecen ser analizadas. En el próximo punto pasaremos a detallar su exégesis en relación a su incorporación normativa, en concordancia con las demás normas aplicables en la materia.

\section{II.- LA UNIFICACIÓN DE LAS RESPONSABILIDADES, Y SU RELACIÓN CON LA NORMA (Art. 1728, CCC)}

Como bien lo hemos señalado a lo largo de distintas publicaciones relacionadas con la presente temática, prima facie resulta apropiado destacar

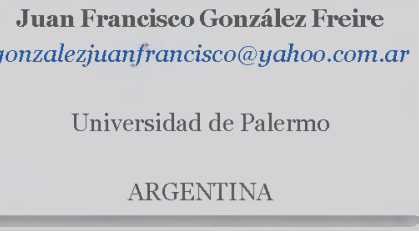

COMO CITAR ESTE ARTÍCULO

González Freire, J. F. (2021). La previsibilidad contractual y sus consecuencias en el Código Civil y Comercial. Revista de la Facultad de Ciencias Económicas, 26(1), 15 - 24. http://dx.doi.org/10.30972/rfce.2615027

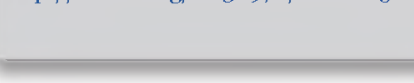


lo sostenido por el Dr. PICASSO ${ }^{1}$ al momento de señalar que mediante los proyectos elaborados en 1987, 1993 y -muy especialmente- 1998, finalmente se unifica la responsabilidad civil contractual y extracontractual. Así, su art. 1716 dispone: "Deber de reparar. La violación del deber de no dañar a otro, o el incumplimiento de una obligación, da lugar a la reparación del daño causado, conforme con las disposiciones de este Código". En otras palabras, cualquiera sea la fuente del deber de reparar el daño (la violación del deber general de no dañar -fuente de la responsabilidad extracontractual - o el incumplimiento de una obligación -fuente de la contractual-), la responsabilidad se rige, en principio, por las mismas reglas.

La unificación de las fuentes obligó a adoptar un criterio distinto del sostenido por el derogado Código de Vélez, en tanto éste imponía la necesidad de que, ante el incumplimiento de una obligación preexistente donde mediaba la culpa del agente, se debía responder por las consecuencias inmediatas y necesarias, de conformidad con el anterior art. 520; comprendiendo las consecuencias mediatas solo ante la existencia de dolo obligacional (cfr. art. 521 del derogado Código). Conforme lo expuesto, se entendía que al mediar un incumplimiento proveniente de una relación contractual, el deudor debía responder por las consecuencias inmediatas y necesarias que ocasionara la frustración de lo pactado, extendiéndose también a la previsibilidad mediata que derive causalmente, cuando el incumplimiento fuera intencional.

El vigente Código Civil y Comercial de la Nación (a través de la Ley 26.994) se aparta de lo contemplado en la saliente Legislación, restringiendo de alguna manera la posibilidad de aplicar desmedidamente las consecuencias dañosas con origen obligacional, salvo que las partes pacten expresamente la indemnización que pueda surgir de las consecuencias mediatas, en razón de haberlas previsto en la contratación, o de entenderse que ello ocurriría por motivos del incumplimiento de la obligación.

Acompañando lo sostenido en análisis a la norma, comparto lo señalado en cuanto a que "el Código no dice consecuencias inmediatas, sino lo que las partes previeron o pudieron haber previsto al momento de su celebración. Queda la duda respecto de la aplicación de lo preceptuado en el 1726, que dispone que la responsabilidad contractual incluye las consecuencias inmediatas o mediatas, salvo disposición legal en contrario. El 1728 puede entenderse como una excepción al 1726, porque la lógica indica que lo normal es que al momento del incumplimiento el deudor asume solo las consecuencias inmediatas. Para que en materia contractual se reparen hasta las consecuencias mediatas, las partes tienen que haberlas previsto o haberlas podido prever al momento de contratar. Si no hay pacto expreso, la carga de demostrar que se previeron las consecuencias mediatas incumbe al acreedor. ${ }^{2}$

En cuanto a la posibilidad de invocar las consecuencias mediatas en razón de un incumplimiento intencional, debe existir el agravante en la conducta del agente respecto a no querer

\footnotetext{
${ }^{1}$ Cfr. PICASSO, Sebastián, "La unificación de la Responsabilidad Civil en el Proyecto de Código Civil y Comercial unificado", Revista Derecho Privado, Año I, Número 3, Ediciones INFOJUS, pág. 33, (id SAIJ DACF130013).-

2 RIVERA, Julio - MEDINA, Graciela, "El Código Civil y Comercial de la Nación comentado", Editorial LA LEY, Buenos Aires, Año 2015, Tomo IV, pág. 1042 y 1043.-
} 
cumplir la obligación. Y es ahí donde opera la apertura del camino hacia la invocación de las consecuencias que la vigente Legislación establece, pudiendo ser -además de las consecuencias inmediatas y necesarias- las mediatas e incluso las casuales (cfr. art. 1727, CCC).

Ello es así, toda vez que "el dolo agrava la situación del incumplidor" y que "Todo indica que la previsión de quién no paga porque no quiere puede abarcar no solo la consecuencia mediata sino la casual si es que se la representó y lo mismo siguió con su plan de no honrar su deuda". Respecto a ello, jurisprudencialmente se ha dicho que "La actitud del comprador que pretende cumplir su prestación a través de la entrega de dos cheques, que al cobro estaban sin fondos, y que además anuncia a su acreedor esa circunstancia, importa un deliberado incumplimiento que por tanto es doloso. Esa circunstancia lo hace responsable de las consecuencias mediatas, que como la analizada tiene una causalidad adecuada, con el referido incumplimiento, puesto que aun cuando sea extrínseca al negocio, de no haber mediado incumplimiento, no hubiera sucedido, $y$ bien pudo haberse previsto, máxime frente a las intimaciones telegráficas efectuadas por el actor". ${ }^{4}$

Siguiendo los efectos de la infracción contractual impuesta por el ordenamiento Velezano, en la medida en que exista una obligación incumplida, habrá responsabilidad del deudor. La misma surgirá como corolario de lo establecido en el vigente art. 1749 ("Responsabilidad Directa”), cuyo criterio de apreciación en el factor de atribución será subjetivo, salvo que exista "imposibilidad de cumplimiento", donde "el deudor podrá exonerarse si acredita que el cumplimiento había devenido imposible en los términos de los arts. 955 y 1732". De conformidad con esas normas, la imposibilidad sobrevenida objetiva y absoluta de la prestación, causada por caso fortuito, tiene un doble efecto: extingue la obligación y, consiguientemente - al no subsistir una obligación incumplida - libera al deudor de responsabilidad. En cuanto a "la ejecución de la obligación por un tercero" (cfr. art. 732, CCC, "actuación de auxiliares - principio de equiparación"), deviene relevante señalar que "cuando el incumplimiento es materializado por un tercero ejecutor de la obligación", el deudor responde en los términos del art. 1749, que regula los casos de responsabilidad directa, y no se aplica el art. 1753, que se refiere a la responsabilidad del principal por el hecho del dependiente y estructura una responsabilidad indirecta. Esta última norma sí rige, en cambio, los supuestos de responsabilidad extracontractual por daños causados por el ejecutor material de la obligación: daños a terceros no contratantes, o bien daños sufridos por el acreedor como consecuencia de la lesión de bienes distintos de los que conforman el objeto del contrato (vgr. daños a la persona del acreedor). Es en este sentido que debe entenderse la referencia que se hace en ese artículo a la responsabilidad del principal por el hecho de "las personas de las cuales se sirve para el cumplimiento de sus obligaciones". ${ }^{5}$

\footnotetext{
${ }^{3}$ RIVERA, Julio - MEDINA, Graciela, "EI Código Civil y Comercial...", Editorial LA LEY, ob. cit., pág. 1043.

${ }^{4}$ CNCiv., SALA E, de fecha 29/07/1985, LA LEY, 1986-A-504.

${ }^{5}$ Cfr. PICASSO, Sebastián, "La unificación de la Responsabilidad Civil en el Proyecto de Código Civil y Comercial unificado", Revista Derecho Privado, Año I, N³, Ediciones INFOJUS, pág. 33 (id SAIJ DACF130013).
} 
Razonando el actual alcance jurídico legislado, se ha puesto de resalto en cuanto a la interpretación de la norma ${ }^{6}$ que el artículo que se comenta sienta una regla de larga data, cuyo origen remonta a dos textos de Paulo ${ }^{7}$ y que fue luego desarrollado durante la edad media y el antiguo Derecho Francés ${ }^{8}$. POTHIER efectuó un aporte definitivo en la materia ${ }^{9}$ que se vería luego reflejado en el artículo 1150 del Código Civil Francés y, por influencia de éste, en la mayoría de sus émulos europeos y americanos, e incluso en el Derecho Anglosajón. ${ }^{10}$

También era éste el sistema original de los artículos 520 y 521 del Código derogado, que, sin embargo, se referían al incumplimiento de cualquier clase de obligaciones (no únicamente a las contractuales) y fueron luego reinterpretados como estableciendo la regla de la causalidad adecuada. ${ }^{11}$

Así, para establecer la extensión del resarcimiento, los artículos 1726 y 1727 del actual Código unificado acuden al sistema de la causalidad adecuada, "en cuya virtud el responsable debe reparar las consecuencias que, en función de las reglas de la experiencia, habrían resultado previsibles para un hombre medio puesto en el momento del hecho. Sin embargo, cuando se trata de contratos negociados entre las partes, esa regla cede su lugar a la que establece el artículo que ahora se comenta (1728), que toma en cuenta las consecuencias que las partes previeron o pudieron prever al tiempo del contrato"..$^{12}$

Es decir, el vigente artículo 1728 adopta un criterio específico en el marco de la responsabilidad, apartándose de lo contemplado mediante los artículos 1726 y 1727, a los efectos de diferenciarse de la responsabilidad genérica. Como lo señala LORENZETTI, "las soluciones que reclama el campo contractual se diferencian en este punto de la tutela aquiliana: la obligación preexistente es un programa de prestación, con un régimen de incentivos, de reparto de riesgos, que sería alterado si luego no se respetara, lo cual disminuiría la cantidad de acuerdo que se generen". ${ }^{13}$

Conforme lo expuesto, el vigente artículo 1728 del Código Civil y Comercial enrostra una limitación hacia las consecuencias jurídicas generadas por el incumplimiento de la obligación,

\footnotetext{
${ }^{6}$ Cfr. LORENZETTI, Ricardo, “Código Civil y Comercial de la Nación comentado", Editorial Rubinzal-Culzoni, Santa Fe, Año 2015, Tomo VIII, pág. 425, (en cita a LORENZETTI, Ricardo, "Tratado de los contratos. Parte general”, pág. 636 y ss.,; CUETO RUA, J., "La imprevisibilidad del daño contractual" (la regla "Hadley vs. Baxendale"), en Revista de la Asociación Argentina de Derecho Comparado, volumen 1, págs. 34-63, 19.

${ }^{7}$ DIGESTO, 19, 1,43 y DIGESTO 19, 1, 21,3, respectivamente. Vid. Sobre el punto PANTALEÓN PRIETO, Fernando, "El sistema de Responsabilidad Contractual" (materiales para un debate), en Anuario de Derecho Civil, Tomo XLIV, fascículo III, Madrid, Año 1991, pág. 1073.

${ }^{8}$ LLAMAS POMBO, "Cumplimiento por equivalente...", cit., págs. 195/916, en especial nota 545.

9 POTHIER, Roberto, "Traié des obligations, en Oeuvres de Pothier", Didot, Paris, 1821, T I, p. 181 y ss.

${ }^{10} \mathrm{Cfr}$. PANTALEÓN PRIETO, "El sistema...", cit., pág. 1079/1085.

11 PICASSO, Sebastián, "Unidad de la Responsabilidad Civil y extensión del resarcimiento", Tercer Congreso Nacional de Derecho Civil, Academia Nacional de Derechos y Ciencias Sociales de Córdoba, Córdoba, Año 2009, Tomo III, págs. 1399 y ss. (citas 7 , $8,9,10$ y 11 , que se remiten a lo citado por el autor cfr. cita 6, LORENZETTI, Ricardo, "Código Civil y Comercial de la Nación comentado", Editorial Rubinzal-Culzoni, Santa Fe, Año 2015, Tomo VIII, pág. 425).

12 LORENZETTI, Ricardo, "Código Civil y Comercial de la Nación comentado", Editorial Rubinzal-Culzoni, Santa Fe, Año 2015 , Tomo VIII, pág. 426.-

${ }^{13}$ LORENZETTI, Ricardo, "Resarcimiento del Daño Contractual: confianza, información, previsibilidad”, en J.A. del 25-4-2001, pág. 56.
} 
con la excepción de que las partes hayan previsto -expresamente, o se entienda que dicho resultado podía preverse- donde recién allí trascendería la aplicación de las consecuencias inmediatas y necesarias, hacia las mediatas y las casuales (cfr. art. 1727, CCC). Vale entenderse ésta última como una excepción a la limitación (art. 1728 del citado ordenamiento), en razón de que las partes han tenido conocimiento de lo que generaría el incumplimiento de la obligación, incurriendo igual en ésta.

Y ello debe ser así, "porque la regla bajo estudio presupone que las partes han podido negociar los términos del contrato y prever de común acuerdo un esquema de riesgos y beneficios..." resaltándose al mismo tiempo que "tampoco se aplica la regla si media dolo del deudor, para lo cual de acuerdo a los amplios términos en los que se define ese factor de atribución en el artículo 1724, basta con el incumplimiento deliberado ("con manifiesta indiferencia"), sin que sea necesaria la prueba de la intención de dañar al acreedor". ${ }^{14}$

Va de suyo entonces que la vigente Legislación codifica específicamente un régimen contractual que no escape del conocimiento de las partes. Los contratantes deben conocer lo más ampliamente posible el alcance dañoso que se genera producto de las consecuencias jurídicas que surgen de su producción; interés éste que surge del incumplimiento del contrato, cuyos obligados no pueden a la postre desconocer lo previsto al momento de su celebración.

Sobre el particular, se tiene dicho que "dentro de la noción de libertad contractual quedan incluidas las facultades de celebrar un contrato, de rehusarse a hacerlo, de elegir el contratante, de determinar su objeto, es decir, de la denominada libertad de autodecisión y autorregulación. Con mayor precisión se puede decir que la libertad de contratación comprende, por un lado, la posibilidad de decidir libremente si vas a celebrar un contrato y con quién hacerlo (libertad de conclusión), y por otro, la posibilidad de establecer el contenido del convenio (libertad de configuración interna)". ${ }^{15}$

Como se puede colegir, las partes tienen amplia libertad de prever cual es el objeto obligacional que satisface el interés de cada una de ellas y arbitrar los medios para asegurar su cumplimiento ${ }^{16}$. Siguiendo los argumentos del autor, "todo contrato contiene distintos tipo de intereses de las partes que procuran su satisfacción mediante el acuerdo de voluntades, están explícitos en el texto del pacto, y por ende, son conocidos por las partes. Estos intereses son los propios del contrato que cuando son incumplidos generan molestias o inquietudes típicas del mundo de los negocios. En cambio, los intereses vinculados al objeto del pacto tienen una relación con el mismo pero no forma parte de las obligaciones e intereses que tipifican el contrato y normalmente no tienen carácter económico. ${ }^{17}$

\footnotetext{
${ }^{14}$ LORENZETTI, Ricardo, "Código Civil y Comercial de la Nación...", ob. cit, pág. 428.

${ }^{15}$ ALFERILLO, Pascual, "Contrato de elaboración por el sistema de maquila-Vino-Caña de Azúcar" Ediciones Jurídicas Cuyo, Mendoza, Año 1994, págs. 52/53.

${ }^{16}$ ALTERINI, Jorge, H., “Código Civil y Comercial de la Nación - Tratado Exegético", Editorial LA LEY, Buenos Aires, Año 2015, Tomo VIII, pág. 124.

${ }^{17}$ ALFERILLO Pascual, "El Daño Moral Contractual y el origen de la ilicitud" LLGran Cuyo, 2011 (marzo) 113.
} 
En función de ello, resulta de lógica jurídica que en los contratos se responda por las consecuencias directas que las partes previeron o pudieron haber previsto al momento de su celebración $^{18}$, pudiendo existir intereses fuera de lo reglado que igualmente resultan importantes para las partes (siempre y cuando las consecuencias que se intenten valer, hayan sido puestas en conocimiento de la parte, o bien puedan deducirse de la naturaleza del pacto, ampliándose el resarcimiento de lo que resulte probarse por el contratante damnificado).

\section{III.- SINOPSIS}

Significativamente, como lo expone GALDOS ${ }^{19}$, la unificación de la responsabilidad civil contractual y extracontractual no significa su homogeneidad, pues subsisten algunas particularidades propias de cada órbita. Una de estas especificidades ronda en la relación de causalidad. Como se sabe, una de las funciones de la relación de causalidad es la de determinar las consecuencias resarcibles, es decir, conectar el incumplimiento -que será incumplimiento obligacional cuando se trate de responsabilidad contractual- con las consecuencias dañosas que de este ilícito se desprenden.

En el vigente ordenamiento la cuestión aparece tratada en el art. 1726, que establece que "excepto disposición legal en contrario, se indemnizan las consecuencias inmediatas y las mediatas previsibles", para lo cual habrá que recurrir a la calificación que efectúa el art. 1727, que sigue la regulación anterior.

Por su parte, el art. 1728 refiere a la "previsibilidad contractual" y establece que "en los contratos se responde por las consecuencias que las partes previeron o pudieron haber previsto al momento de su celebración". Sólo si se evidencia "dolo del deudor", la responsabilidad se fija tomando en cuenta "las consecuencias también al momento del incumplimiento".

En concreto, el artículo 1728 del CCC adopta el parámetro de previsibilidad para la responsabilidad contractual, mientras que los arts. 1726 y 1727 del citado cuerpo legal, determinan la regla de la relación de causalidad adecuada para la órbita extracontractual. Por consiguiente, las categorías definidas en el art. 1727 del CCC (consecuencias inmediatas, mediatas, y casuales), no resultan de aplicación para efectuar el juicio de previsibilidad ${ }^{2 \circ}$, el que se realiza con referencia a lo que las partes previeron efectivamente o pudieron prever

\footnotetext{
${ }^{18}$ ALTERINI, Jorge, H., "Código Civil y Comercial de la Nación - Tratado Exegético", Editorial LA LEY, Buenos Aires, Año 2015, Tomo VIII, pág. 124.

${ }^{19} \mathrm{Cfr}$. GALDOS, Mario - VALICENTI Ezequiel, “La reparación del daño y la previsibilidad contractual (el art $1728 \mathrm{CCCN}$ )", publicado en Www.nuevocodigocivil.com

${ }^{20}$ En similar sentido, PICASSO, Sebastián - "La unificación de la responsabilidad civil en el Proyecto de Código Civil y Comercial unificado", en Revista Derecho Privado, año I, n³, Reformas al Código Civil Il. Obligaciones y responsabilidad, INFOJUS, Bs. As., Año 2012, pág. 82.
} 
al momento de la celebración del contrato a lo que, cuando se tratare de un caso de incumplimiento doloso, se adicionarán las consecuencias que se previeron o pudieron preverse al momento del incumplimiento.

Por lo demás, conviene precisar que el juicio de previsibilidad del art. 1728 del CCC se refiere únicamente a los contratos paritarios o negociados, en los que rige plenamente la autonomía privada para delimitar las obligaciones asumidas por cada una de las partes y, por ello, de prever las consecuencias del eventual incumplimiento. ${ }^{21}$

Ello excluye la aplicación a: los contratos de consumo, y, por los mismos fundamentos, a los contratos que son celebrados por adhesión a cláusulas generales predispuestas; los casos en que se trata de un incumplimiento doloso; los daños provocados a la persona con motivo del contrato. Frente a estas hipótesis, la reparación se rige por las reglas generales de la relación de causalidad previstas para la responsabilidad extracontractual, y queda descartada la aplicación de la previsibilidad contractual.

En cuanto a la doctrina elaborada por los tribunales durante la vigencia del régimen anterior, solo mantienen vigor aquellas que responsabilizan al deudor de las consecuencias contractuales previsibles. Así, según ALTERINI ${ }^{23}$, se puede citar que "la responsabilidad frente a un incumplimiento de carácter contractual debe surgir de la existencia de un contrato previo y válido no cumplido; pues ello va a delimitar aquella, ya que el deudor por su incumplimiento culposo debe responder únicamente por aquellos daños que sean consecuencia inmediata y necesaria de la falta de ejecución de la obligación". ${ }^{24}$

De igual modo "una circunstancia decisiva que juega como uno de los factores de la responsabilidad en materia contractual, es la relación de causalidad que debe existir entre la inejecución del contrato y el daño producido. En el campo de la responsabilidad contractual, la extensión del resarcimiento alcanza a los daños que fueren consecuencia inmediata y necesaria de la falta de cumplimiento de la obligación. Por consiguiente, quedan excluidos otros daños indirectos que fueren consecuencia solo mediata y no necesaria de la inejecución del deudor" ${ }^{25}$. "La extensión del resarcimiento en la órbita de la responsabilidad contractual -en el caso, por incumplimiento de las prestaciones del servicio de energía eléctrica ante cortes sufridos por la actora (...) con arreglo al cual en el resarcimiento de los daños e intereses solo se comprenderán los que fueren consecuencia inmediata y necesaria del incumplimiento de la

\footnotetext{
${ }^{21}$ Conf., "Fundamentos del Anteproyecto de Código Civil y Comercial de la Nación elaborados por la Comisión Redactora", en Proyecto de Código Civil y Comercial de la Nación, Infojus, Bs. As., 2012; PICASSO, Sebastián - "Comentario al art. 1728", en LORENZETTI, Ricardo (dir) - DE LORENZO, Federico y LORENZETTI, Pablo (coords.) - Código Civil y Comercial Comentado, Rubinzal-Culzoni, Santa Fe, 2015, p. 424.; Azar, Aldo M. - “La relación causal en el Proyecto de Código Civil y Comercial” cit., pág. 32; GALDÓS, Jorge M., en colaboración con BLANCO, Gustavo - "Diferencias entre la responsabilidad civil contractual y extracontractual..." cit., pág. 275.

22 LORENZETTI, Ricardo L. - "Tratado de los Contratos. Parte General”, Rubinzal-Culzoni, Santa Fe, Año 2004, p. 626; SOZZO, Gonzalo - "Antes del contrato" - Lexis-Nexis, Bs. As., 2005, p. 234 (cfr. citas 20, 21 y 22, correspondientes a GALDOS, Mario - VALICENTI E., "La reparación del daño y la previsibilidad contractual (el art $1728 \mathrm{CCCN}$ )", ob. cit., publicado en www.nuevocodigocivil.com

${ }^{23}$ ALTERINI, Jorge, H., "Código Civil y Comercial de la Nación - Tratado Exegético", Editorial LA LEY, Buenos Aires, Año 2015, Tomo VIII, pág. 126.-

${ }^{24}$ CFed., CORDOBA, de fecha 27/05/1983, cfr, autos "Brizuela, Ángel c/LV 3 Radio Cór doba y otro".-

${ }^{25}$ CNCom., SALA C, 24/04/92, "Frydlewski, Marcelo c/Harriet y Welsh” LA LEY, 1993-A-85; DJ, 1993-1-552.
} 
obligación"26. Concibiendo que las consecuencias solo podrían extenderse ante un incumplimiento malicioso (es decir, mediando dolo).

Finalmente - del mismo modo en que lo hemos efectuado en otras publicaciones relacionadas con la presente temática, compartimos las siguientes conclusiones -arribadas por el autor- en relación con la regulación de la "previsibilidad contractual", en función de la citada norma y su desarrollo ${ }^{27}$ :

El artículo 1728 del CCC incorpora el criterio de la previsibilidad contractual como mecanismo jurídico para delimitar las consecuencias resarcibles en caso de incumplimiento obligacional. La ponderación del juicio de previsibilidad deberá efectuarse en base a los siguientes parámetros:

a) Debe evaluarse según un parámetro subjetivo, que permita determinar lo que el contratante obligado previó efectivamente o pudo razonablemente prever según las circunstancias concretas del caso al momento de contratar.

b) La posibilidad de prever se define según el conocimiento con el que contaban las partes al momento de contratar. Se tendrán por conocidas las circunstancias ordinarias, esto es, las comúnmente usuales o habituales (las que son de público conocimiento, art. 1727) o las que debieron serlo por la naturaleza del acto (objeto y finalidad), o por las condiciones particulares del deudor (art. 1725, CCC). Para que otras circunstancias excepcionales y propias del contrato en particular se tengan por efectivamente conocidas o conocibles deberán ser comunicadas a la otra parte - directa o indirectamente- al momento de contratar, pues su conocimiento no puede presumirse.

c) El juicio de previsibilidad se enfoca a la trama obligacional del contrato determinada por el objeto, la causa y el tipo contractual (arts. 961 y 281 del CCC).

d) La previsibilidad se vincula con la cognosibilidad, que es un presupuesto fáctico temporalmente anterior, de modo que se puede o no prever según se pueda o no conocer.

e) Es suficiente con que haya resultado previsto o previsible la naturaleza del daño, aunque no su extensión.

f) El juicio de previsibilidad queda desplazado cuando se trata de un contrato de consumo o de un contrato celebrado por adhesión a cláusulas generales predispuestas o cuando el incumplimiento es doloso o cuando como consecuencia del contrato se causan daños a la persona. Para éstos casos rigen las reglas de la relación de causalidad previstas para la responsabilidad de órbita extracontractual.

g) En caso de dolo, la reparación se determina también según las consecuencias previsibles al momento del incumplimiento.

h) Mientras "la probabilidad" se vincula más bien con un análisis objetivo, el juicio de previsibilidad obedece a un criterio subjetivo y concreto.

\footnotetext{
${ }^{26}$ CNCiv., y Com. Fed., SALA II, 07/02/2006, "Macchia María c/Edesur S.A. y otro", DJ., pág. 1043.

${ }^{27}$ Cfr. CALVO COSTA, Carlos, "Doctrina y Estrategias del Código Civil y Comercial” Editorial LA LEY, Buenos Aires, Año 2016, Tomo V, pág 256 (mediante cita del artículo comentado por Jorge GALDOS)
} 
i) El lucro cesante y la pérdida de chance son consecuencias resarcibles indemnizables que tienen en común, aunque con distinto grado de intensidad, a la probabilidad.

j) El principio objetivo de la normalidad previsto en el art. 1727 del CCC, aunque es propio de la causalidad adecuada (arts. 1726 y 1727, CCC), también resulta una valiosa herramienta de interpretación coadyuvante en materia de previsibilidad contractual prevista en el art. 1728 CCC.

k) Si bien la clasificación de las consecuencias en mediatas, inmediatas y casuales carece de efecto normativo en el juicio de previsibilidad contractual y no constituyen categorías compatibles y aplicables al incumplimiento obligacional, conservan valor dogmático a los efectos de desentrañar la naturaleza de las consecuencias dañosas.

También adquiere relevancia señalar las concordancias de la norma en juego, tales como: "la libertad de contratación (art. 958), la buena fe (art. 961), los factores subjetivos (art. 1724), la relación causal (art. 1726), el tipo de consecuencias (art. 1727), el hecho del damnificado (art. 1729), el caso fortuito o fuerza mayor (art. 1730), el hecho de un tercero (art. 1731), la imposibilidad de cumplimiento (art. 955 y 1732)...". ${ }^{28}$

Culminando el presente análisis, independientemente del vicio en la voluntad que se podría, o no invocar (pues se trata puntualmente de concebir el alcance de las consecuencias que generaría la infracción obligacional), el discernimiento juega un papel preponderante, en razón de que el juicio de previsibilidad -es decir, la posibilidad de prever consecuencias dañosas que efectúa el deudor al contratar-, depende de un elemento cognitivo. Sobre la base del conocimiento disponible al contratar podrá efectuarse la previsión de las consecuencias dañosas del incumplimiento. ${ }^{29}$

\section{CURRICULUM VITAE}

\section{Juan Francisco González Freire}

Abogado. Doctrinario. Docente Universitario. Director del área jurídica (suplemento) de "Obligaciones, Responsabilidad civil y Derechos de Daños" de la Editorial elDial.com. Autor de bibliografías, tales como "La Responsabilidad Civil en el Código Civil y Comercial de la Nación", 1ra., 2da., y 3ra. edición, Editorial Albremática, años 2018 y 2020; "El Derecho de Daños frente al COVID-19", Editorial Albremática, año 2020. Coautor de "Cuestiones Proce-

\footnotetext{
${ }^{28}$ LORENZETTI, Ricardo, "Código Civil y Comercial de la Nación comentado", Editorial Rubinzal-Culzoni, Santa Fe, Año 2015, Tomo VIII, págs. 424/425.-

${ }_{29} \mathrm{Cfr}$. ACCIARRI, Hugo, "La relación de causalidad y las funciones del Derecho de Daños", Editorial Abeledo-Perrot, Buenos Aires, Año 2009, pág. 79; También, ALTERINI, Atilio A., AMEAL, Oscar J. y LÓPEZ CABANA, Roberto, "Derecho de Obligaciones", Editorial Abeledo Perrot, $2^{\circ}$ edición, Buenos Aires, Año 1998, pág. 28.; En el mismo sentido, PIZARRO, Ramón y VALLESPINOS, Gustavo, "Instituciones de Derecho Privado. Obligaciones", Editorial Hammurabi, Año 1999, Tomo 3º pág. 171.-
} 
sales en el Código Civil y Comercial", Editorial Albremática, año 2018. Autor de diversos artículos publicados en Editoriales El Derecho, La Ley (Thomson Reuters); elDial.com; Erreius, IJ Editores; Dialnet (Universidad de La Rioja, Logroño, España). Disertante en Colegios de Abogados y Universidades Nacionales, en Asociaciones de Abogados y Departamentos Judiciales. Autor de diferentes propuestas de Reformas Legislativas parciales presentadas ante el Ministerio de Justicia y Derechos Humanos de la Nación, respecto de los arts. 1771, 1775, inc. c), 1780 , inc. b), 2561, 1er párrafo y 1749 del CCCN (complementarias al proyecto de Reforma vigente Código Civil y Comercial, Ley 26.994).

gonzalezjuanfrancisco@yahoo.com.ar 